\title{
Prevalence and Risk Factors for Bacterial Vaginosis and Other Vulvovaginitis in a Population of Sexually Active Adolescents from Salvador, Bahia, Brazil
}

\author{
Rita Elizabeth Moreira Mascarenhas, ${ }^{1,2}$ Márcia Sacramento Cunha Machado, ${ }^{1}$ \\ Bruno Fernando Borges da Costa e Silva, ${ }^{1}$ Rodrigo Fernandes Weyll Pimentel, ${ }^{1}$ \\ Tatiana Teixeira Ferreira, ${ }^{1}$ Fernanda Maria Silva Leoni, ${ }^{1}$ and Maria Fernanda Rios Grassi ${ }^{1,2}$ \\ ${ }^{1}$ Department of Obstetrics \& Gynecology, Bahiana School of Medicine and Public Health (EBMSP), 40290-000 Salvador, BA, Brazil \\ ${ }^{2}$ Advanced Laboratory of Public Health (CPQGM), Oswaldo Cruz Foundation (FIOCRUZ), 40296-710 Salvador, BA, Brazil \\ Correspondence should be addressed to Rita Elizabeth Moreira Mascarenhas, rita@conveniado.bahia.fiocruz.br
}

Received 6 July 2012; Revised 6 September 2012; Accepted 20 September 2012

Academic Editor: Catherine L. Haggerty

Copyright () 2012 Rita Elizabeth Moreira Mascarenhas et al. This is an open access article distributed under the Creative Commons Attribution License, which permits unrestricted use, distribution, and reproduction in any medium, provided the original work is properly cited.

\begin{abstract}
Bacterial vaginosis, trichomoniasis, and genital candidiasis are considered the main etiologies of vulvovaginitis. Few studies estimate the prevalence of vulvovaginitis among adolescents, especially in Brazil. This study aimed to determine the prevalence and main risk factors associated with bacterial vaginosis and genital infection by C. albicans and Trichomonas vaginalis among a group of adolescents from Salvador, Bahia, Brazil. One hundred sexually active adolescents followed at an adolescent gynecology clinic were included. Endocervical and vaginal samples were obtained during gynecological examination. Nugent criteria were applied for the diagnosis of bacterial vaginosis. For Candida albicans and Trichomonas vaginalis detection, culture in Sabouraud agar plates and Papanicolaou cytology were used, respectively. The mean age of participants was $16.6 \pm 1.6$ years. The prevalence of bacterial vaginosis was $20 \%$ (95\% CI 12-28) and of genital infection by Candida was 22\% (95\% CI 14-30). Vaginal cytology detected Trichomonas vaginalis in one patient. Alcohol, tobacco, and illegal drug use $(P=0.02)$ and multiple lifetime partners were statistically related to bacterial vaginosis $(P=0.01)$. The prevalence of bacterial vaginosis and genital candidiasis was similar to other studies carried out among adolescents worldwide.
\end{abstract}

\section{Introduction}

Sexually transmitted diseases (STDs) are prevalent, it is estimated that 340 million new cases occur among adults worldwide [1]. These conditions are also regarded as an important public health problem for its medical, social and economic implications [2]. Vaginal infection is one of the most common gynecological affections and vaginal discharge is one of the most common reasons for which women seek medical attention [3]. Vulvovaginitis is a usual cause of genital infection in women. Bacterial vaginosis, Candida albicans genital infection and trichomoniasis are considered the main etiologies of vulvovaginitis $[4,5]$.

Bacterial vaginosis is a dysbiosis, in which a decrease in resident vaginal lactobacilli is associated with a growth of anaerobic polymicrobial flora. Bacterial vaginosis is not considered a STD, being usually described, however, as a sexually enhanced disease, in which the frequency of intercourse plays a critical role [6]. Furthermore, bacterial vaginosis has been associated with increased susceptibility to HIV-AIDS and other STD [7].

Candida genital infection is the leading cause of fungal vulvovaginitis. Pregnancy, broad-spectrum antibiotic use, diabetes mellitus, and immunodeficiency have been described as important risk factors for Candida genital infection; however, asymptomatic microorganism colonization can occur in 25 to $50 \%$ of the cases $[4,8,9]$.

Trichomonas vaginitis is often transmitted by sexual intercourse. It is the most common sexually transmitted pathogen, accounting for 180 million infections annually 
[10]. The classical symptoms associated with the T. vaginalis infection include a yellowish-green frothy discharge, pruritis, dysuria, and the "strawberry" cervix which is characterized by punctuate hemorrhagic lesions.

The specific causes and risk factors associated with bacterial vaginitis are poorly understood; however, associations with sexual activity, use of hygiene products that alter the vaginal ecosystem, and genetic predisposition have been described $[11,12]$. If undiagnosed or untreated, these infections might interfere with the women's reproductive health, being commonly associated with many obstetric conditions such as pelvic inflammatory disease (PID), premature rupture of membranes (PROM), prematurity, and infertility $[4,5]$ and also increasing the risk of HIV-1 transmission.

Adolescence is a stage of physical and psychological transformation and behavioral experimentation, also being associated with risky sexual behavior in regards to STDs $[12,13]$. During this period of life, reproductive hormones cause considerable physiological and tissue changes, which may increase susceptibility to infections. At this stage, the cylindrical epithelium of the endocervical channel is more ectopic and exposed to various agents that commonly infect these tissues [2, 14]. In Brazil, adolescents account for approximately $11 \%$ of the population [15]. Few studies have determined the prevalence of vulvovaginitis and associated risk factors among adolescents in Brazil. This population's health is considered a priority by the National Health Agenda of the Brazilian Ministry of Health.

The goal of this study was to determine the prevalence and main risk factors associated with bacterial vaginosis, $C$. albicans genital infection, and trichomoniasis in a group of female adolescents from Salvador, Bahia, Brazil.

\section{Materials and Methods}

This is a cross-sectional study involving 100 sexually active adolescents followed in the Adolescent Gynecology Clinic (Serviço de Ginecologia da Infância e Adolescência-SEGIA) of Escola Bahiana de Medicina e Saúde Pública (EBMSPSalvador, Bahia, Brazil), included between September 2008 and August 2010. By the time of enrollment, all participants have had at least one sexual partner in their lifetime, being considered sexually active. SEGIA is an outpatient clinic that as been offering complete gynecological care to 356 patients since 2008. By August 2010, approximately $37 \%$ of patients followed in the clinic were sexually active.

Patients were included sequentially at the time of gynecological appointment. Inclusion criteria were female gender, age between 10 and 19, years and sexual activity. Pregnancy, puerperium, and intravaginal medication use were adopted as exclusion criteria. The study was approved by the Institutional Review Board of EBMSP. An informed consent form was applied and signed by all the legally responsible persons for the adolescents prior to their participation in the study. The patients with 18 years of age or older signed it themselves. All principles outlined in the Declaration of Helsinki were followed.

The clinical and demographic data were obtained by applying a semistructured questionnaire. Then, the patients were submitted to gynecological examination. To analyze the growth of Candida species, samples were collected using a vaginal swab dampened with sterile saline, plated aseptically on Sabouraud Dextrose Agar plates (Acumedia Neogene, Lansing, Michigan, USA) and incubated at $35^{\circ} \mathrm{C}$ for 24 to 48 hours. White, circular, medium-sized, and catalase positive colonies, observed as Gram-positive yeast in Gram staining, were tested for identification of Candida albicans. Positive germ tube test and green stain in CHROMagar Candida (Difco-Becton Dickinson Microbiolgy Systems, Maryland, USA) medium are indicative of these species. The strains that have been tested negative for the germ tube test and have not stained green in the CHROMagar medium were identified as Candida spp.

Smears prepared with vaginal and endocervical specimens collected during pelvic examination were Gram stained and observed through optical microscopes (1000X magnification) by two microbiologists. In order to make the diagnosis of bacterial vaginosis, the bacterioscopy was analyzed according to the scoring system proposed by Nugent et al. [16]. The total score ranges from 0 to 10 . BV was diagnosed when the score was equal or higher than seven points.

The diagnosis of genital Trichomonas vaginalis infection was made with vaginal cytology using the Papanicolaou's technique. Protozoan were identified by their morphological aspects (rounded, pyriform or irregular structures, measuring 10 to $20 \mathrm{um}$, cyanophilic cytoplasm and eccentric small nuclei).

Descriptive analysis of all variables was performed, including frequency distributions for ethnic groups, family income, conjugal status, education, alcohol, tobacco and illegal drug use, age at first sexual intercourse, age at menarche, sexual abuse, use of contraceptives, condom use, and number of sexual partners. The prevalence was calculated with a confidence interval of $95 \%$. Chi-square or Fisher's exact tests were used for the analysis of categorical variables. Students $t$ test was used to analyze the numeric data. A value of $P \leq 0.05$ was considered statistically significant. All data were analyzed using the SPSS 17.0 software (IBM SPSS, Chicago, IL, USA) for Windows.

\section{Results}

One hundred patients were included in this study and all patients invited accepted to participate. The mean age of these individuals was $16.6 \pm 1.6$ years; $91 \%$ were nonwhite and $80 \%$ were married or living with a partner; $55 \%$ had more than nine years of education; $49 \%$ belonged to families with incomes equal to or less than one minimum wage (Table 1).

The prevalence of bacterial vaginosis was $20 \%(95 \%$ CI 12-28) and genital infection by Candida albicans or Candida spp. was 22\% (95\% CI 14-30). Only one patient had genital Trichomonas vaginalis infection. Coinfections by Candida species and T. vaginalis and C. albicans and bacterial vaginosis were observed in two adolescents.

Alcohol, tobacco, and illegal drug use was associated with the diagnosis of bacterial vaginosis $(P=0.02)$. Patients 
TABLE 1: Sociodemographic and behavioral characteristics of the study population, stratified by the presence or absence of bacterial vaginosis or genital Candida albicans infection.

\begin{tabular}{|c|c|c|c|c|c|c|c|}
\hline & \multirow{2}{*}{$n=100$} & \multicolumn{3}{|c|}{ Bacterial vaginosis $^{\dagger}$} & \multicolumn{3}{|c|}{ Candida albicans $\S$} \\
\hline & & Negative $(n=80)$ & Positive $(n=20)$ & $P$ & Negative $(n=78)$ & Positive $(n=22)$ & $P$ \\
\hline Age (years) & $16.6 \pm 1.6$ & $16.6 \pm 1.6$ & $16.6 \pm 1.6$ & 0.88 & $16.6 \pm 1.7$ & $16.8 \pm 1.4$ & 0.49 \\
\hline Ethnic group & & & & 1 & & & 1 \\
\hline Nonwhite & 91 & $73(91.2)$ & $18(90)$ & & $71(91)$ & $20(90.9)$ & \\
\hline White & 9 & $7(8.8)$ & $2(10)$ & & $7(9)$ & $2(9.1)$ & \\
\hline Conjugal status & & & & 0.54 & & & 1 \\
\hline Married/living together & 80 & $65(81.2)$ & $15(75)$ & & $16(20.5)$ & $18(81.8)$ & \\
\hline Single & 20 & $15(18.8)$ & $5(25)$ & & $62(79.5)$ & $4(18.2)$ & \\
\hline Family income (minimum wages) & & & & 0.64 & & & 1 \\
\hline 1 & 49 & $40(50)$ & $9(45)$ & & $38(48.7)$ & $11(50)$ & \\
\hline 2 to 4 & 47 & $37(46.3)$ & $10(50)$ & & $36(46.2)$ & $11(50)$ & \\
\hline$\geq 5$ & 3 & $2(2.5)$ & $1(5)$ & & $3(3.8)$ & 0 & \\
\hline Education" & & & & 0.28 & & & 0.28 \\
\hline$<9$ years (primary/intermediate) & 44 & $33(41.3)$ & $11(55)$ & & $31(41)$ & $12(54.5)$ & \\
\hline$\geq 9$ years (secondary/higher) & 55 & $46(57.5)$ & $9(45)$ & & $45(57.7)$ & $10(45.5)$ & \\
\hline Alcohol, tobacco, and illegal drug use & 52 & $37(46.3)$ & $15(75)$ & $0.02^{*}$ & $42(53.8)$ & $10(45.5)$ & 0.48 \\
\hline Age at menarche $(\text { years })^{\ddagger}$ & $12.3 \pm 1.6$ & $12.4 \pm 1.5$ & $12 \pm 2.1$ & 0.55 & $12.4 \pm 1.7$ & $12.2 \pm 1.4$ & 0.67 \\
\hline Age at first sexual intercourse (years) & & & & 0.24 & & & 0.80 \\
\hline$\leq 14$ & 34 & $25(31.3)$ & $9(45)$ & & $27(34.6)$ & $7(31.8)$ & \\
\hline$\geq 15$ & 66 & $55(68.8)$ & $11(55)$ & & $51(65.4)$ & $15(68.2)$ & \\
\hline Sexual abuse & 3 & $2(2.5)$ & $1(5)$ & 0.49 & $3(3.8)$ & 0 & 1 \\
\hline Contraceptive use & 41 & $33(41.3)$ & $8(40)$ & 0.91 & $33(42.3)$ & $8(36.4)$ & 0.61 \\
\hline Condom use & & & & 0.84 & & & 0.75 \\
\hline Never/sometimes & 53 & $42(52.5)$ & $11(55)$ & & $42(53.8)$ & $11(50)$ & \\
\hline Always/Almost always & 47 & $38(47.5)$ & $9(45)$ & & $36(46.2)$ & $11(50)$ & \\
\hline Number of sexual partners & & & & $0.01^{*}$ & & & 0.18 \\
\hline 1 & 55 & $49(61.3)$ & $6(30)$ & & $39(50)$ & $16(72.7)$ & \\
\hline 2 to 4 & 37 & $26(32.5)$ & $11(55)$ & & $32(41)$ & $5(22.7)$ & \\
\hline$\geq 5$ & 7 & $4(5)$ & $3(15)$ & & $6(7.7)$ & $1(4.5)$ & \\
\hline
\end{tabular}

Data are presented as mean $\pm \mathrm{SD}$ (standard deviation) for numeric variables and $n(\%)$ for categorical variables.

$*$ A $P$ value $\leq 0.05$ was considered statistically significant.

${ }^{\dagger}$ The Nugent criteria was used for diagnosis.

$\S$ Vaginal and/or endocervical.

"Data was available for 99 subjects. One minimal wage is approximately 330 US Dollars.

${ }^{\ddagger}$ The specific age at menarche was available for 59 subjects, being $\leq 16$ for all participants.

with bacterial vaginosis reported a higher number of sexual partners when compared to those without the disease $(P=$ 0.01) (Table 1).

Signs and symptoms associated with bacterial vaginosis and genital infection by Candida species are shown in Table 2. Vaginal discharge was the clinical sign most frequently observed in patients with bacterial vaginosis (45\%) and Candida infection (68.2\%). Genital itching, dysmenorrhea, and genital lesions were found in $10 \%$ of patients with bacterial vaginosis. Only $9.1 \%$ of patients with Candida reported genital itching. $13.3 \%$ of these patients also complained about injuries and/or genital hyperemia. The patient infected with $T$. vaginalis presented with a white, odorless, and bullous vaginal discharge (data not shown).

\section{Discussion}

Bacterial vaginosis and genital Candida infection were present in almost a quarter of patients. These prevalences were similar to those reported in other studies involving adolescents in Brazil and other countries [2, 8, 17-19]. In our study, the rate of Trichomonas vaginalis infection was low, about $1 \%$. In Brazil, the prevalence of T. vaginalis was $3.2 \%$ in women aged form 18 to 40 years followed at a primary care health service [20]. The literature unveils great variability in the prevalence rates of trichomoniasis, that may be due to heterogeneity regarding the diagnostic methods used and the group evaluated. Despite its clinical applicability, vaginal cytology has lower sensitivity and specificity rates 
TABLE 2: Current genitourinary signs and symptoms of the study population, stratified by the diagnosis of bacterial vaginosis (BV) or genital Candida albicans infection $(n=99)$.

\begin{tabular}{|c|c|c|c|c|}
\hline & \multicolumn{2}{|c|}{ Bacterial vaginosis $^{\dagger} n=20$} & \multicolumn{2}{|c|}{ Candida albicans $\$ \& \quad n=22$} \\
\hline & $n(\%)$ & $P$ & $n(\%)$ & $P$ \\
\hline Vaginal discharge & $9(45)$ & 0.72 & $15(68.2)$ & $0.03 *$ \\
\hline Genital itching & $2(10)$ & 1 & $2(9.1)$ & 1 \\
\hline Dysmenorrhea & $2(10)$ & 1 & $1(4.5)$ & 0.45 \\
\hline Abdominal/pelvic pain & 0 & 0.34 & $2(9.1)$ & 0.61 \\
\hline Dysuria & 0 & 1 & 0 & 1 \\
\hline Genital lesions and/or vaginal hyperemia & $2(10)$ & 1 & $3(13.6)$ & 0.41 \\
\hline
\end{tabular}

*A $P$ value $\leq 0.05$ was considered statistically significant. The group of patients with bacterial vaginosis and genital candidiasis were compared with the respective groups of uninfected patients.

${ }^{\dagger}$ The Nugent citeria was used for diagnosis.

$\S$ Vaginal and/or endocervical.

$\&_{4}$ of the these 22 patients were diagnosed with Candida spp.

for diagnosing T. vaginalis when compared to parasitological and molecular diagnosis, such as direct microscopy, the culture, and polymerase chain reaction $[21,22]$. Sutton et al. [23], using molecular techniques, reported a prevalence of $2.1 \%$ in a population of 1416 adolescents aged $14-19$ years from non-hispanic white, nonHispanic black, and MexicanAmerican ethnicity. On the other hand, Krashin et al. [14] and Crosby et al. [24], also in the United States, reported higher prevalence rates, $12.9 \%$ and $14.4 \%$, respectively. Both studies used culture methods to detect $T$. vaginalis and were carried out among socioeconomically disadvantaged adolescents, mostly nonwhite patients, that attended public outpatient clinics, similar to the ones included in our study. However, the individuals included in these studies reported a high frequency of sexual intercourse with nonsteady, older partners [14, 24], significant history of delinquency and illegal drug use [24], and concurrent Neisseria gonorrhoeae infection [4], characteristics that differentiate these adolescents from our population.

The presence of bacterial vaginosis was associated with multiple sexual partners $(P=0.01)$. In spite of the fact that bacterial vaginosis is not considered an STD, a greater risk for being diagnosed with this disease has been identified in patients with multiple sexual partners, which is consistent with our study [11]. In this sense, due to the number of sexual partners, in association with the commonly described irregular condom use among this population, one could infer that these adolescents were likely at increased risk for other STDs. Furthermore, male sexual partners may serve as carriers of anaerobic bacteria that cause bacterial vaginosis; the higher incidence of bacterial vaginosis among women with uncircumcised partners reinforces this hypothesis, since the presence of foreskin facilitates the conduction of microorganisms during intercourse [11].

The use of alcohol, tobacco, and illegal drugs was found be associated with bacterial vaginosis. However, it should be interpreted as an indirect risk factor for bacterial vaginosis, since the use of these substances is usually related to practices such as irregular condoms use and poor genital hygiene, that foster the development of this condition [11, 12]. Genital infection by Candida albicans was not associated with any of the risk factors evaluated, although some studies have reported that oral sex and sexual activity are important risk factors for genital infection by this microorganism $[8,18$, 25].

Vulvovaginitis is an important public health problem, not only due to the gynecological and obstetric complications associated with it $[4,5]$ but also because the inflammation of the vaginal mucosa and the reduction of lactobacilli could facilitate the transmission of STDs, especially HIV infection [26, 27]. Moreover, the studied population showed a low frequency of condom use and a high number of sexual partners, behaviors that could lead to an important increase in the risk for STDs among these adolescents.

Regarding the method for the diagnosis of bacterial vaginosis, although Amsel's criteria are more often used in the clinical setting [28], the Nugent scoring system has a higher reproducibility [29], with comparable sensitivity and specificity to the former criteria $[28,30,31]$.

This study is limited by its small sample size and the fact that a less reliable test was used for the diagnosis of $T$. vaginalis and might not reflect the real prevalence of this infection. Additionally, the small sample size can limit inference of results to other similarly aged adolescents from different regions of Brazil and the world.

\section{Conclusions}

In summary, the results obtained demonstrated a high prevalence of bacterial vaginosis and genital candidiasis among adolescents in a disadvantaged social environment of the third largest city in Brazil. If undiagnosed and untreated, these conditions may lead to major obstetric and gynecological complications, which considerably increase treatment costs and hospitalizations and also have a negative impact on female mortality rates. Adolescent medical care requires a multidisciplinary expertise, which guarantees motivation and enhances information quality about STDs and contraceptive methods. Programs that address these aspects could efficiently promote health to adolescents, significantly reducing STDs and unplanned pregnancy rates among this population. 


\section{Conflict of Interests}

The authors declare no conflict of interests.

\section{Acknowledgments}

This study was conducted at the Postgraduation in Medicine and Human Health program of Escola Bahiana de Medicina e Saúde Pública-EBMSP, Salvador, Bahia, Brazil, and funded by the Fundação de Amparo à Pesquisa do Estado da Bahia (Fapesb), Bahia, Brazil. The authors thank Cibele A Souza and Marina Borba Moreira, for technical assistance and Paula Matos, M.D., for critically reading and assisting in the writing of this paper.

\section{References}

[1] World Health Organization, "Global Prevalence and Incidence of Selected Curable Sexually Transmitted Infections Overview and Estimates," New York, NY, USA, 2001.

[2] V. D. A. Tanaka, L. J. Fagundes, A. Catapan, S. L. D. Gotlieb, W. Belda Jr., M. Arnone et al., "Perfil epidemiológico de mulheres com vaginose bacteriana, atendidas em um ambulatório de doenças sexualmente transmissíveis, em São Paulo, SP," Anais Brasileiros de Dermatologia, vol. 82, no. 1, pp. 41-46, 2007.

[3] J. Wang, "Bacterial vaginosis," Primary Care Update for Ob/Gyns, vol. 7, no. 5, pp. 181-185, 2000.

[4] T. S. Syed and P. K. Braverman, "Vaginitis in adolescents," Adolescent Medicine Clinics, vol. 15, no. 2, pp. 235-251, 2004.

[5] P. Nyirjesy, "Vaginitis in the adolescent patient," Pediatric Clinics of North America, vol. 46, no. 4, pp. 733-745, 1999.

[6] H. Verstraelen, R. Verhelst, M. Vaneechoutte, and M. Temmerman, "The epidemiology of bacterial vaginosis in relation to sexual behaviour," BMC Infectious Diseases, vol. 10, no. 1, article 81, 2010.

[7] M. Morris, A. Nicoll, I. Simms, J. Wilson, and M. Catchpole, "Bacterial vaginosis: a public health review," BJOG: An International Journal of Obstetrics \& Gynaecology, vol. 108, no. 5, pp. 439-450, 2001.

[8] A. M. Geiger, B. Foxman, and B. W. Gillespie, "The epidemiology of vulvovaginal candidiasis among university students," American Journal of Public Health, vol. 85, no. 8, part 1, pp. 1146-1148, 1995.

[9] J. P. Trama, M. E. Adelson, I. Raphaelli, S. M. Stemmer, and E. Mordechai, "Detection of Candida species in vaginal samples in a clinical laboratory setting," Infectious Diseases in Obstetrics and Gynecology, vol. 13, no. 2, pp. 63-67, 2005.

[10] H. L. Kent, "Epidemiology of vaginitis," American Journal of Obstetrics \& Gynecology, vol. 165, no. 4, part 2, pp. 1168-1176, 1991.

[11] K. A. Fethers, C. K. Fairley, J. S. Hocking, L. C. Gurrin, and C. S. Bradshaw, "Sexual risk factors and bacterial vaginosis: a systematic review and meta-analysis," Clinical Infectious Diseases, vol. 47, no. 11, pp. 1426-1435, 2008.

[12] M. Vaca, I. Guadalupe, S. Erazo et al., "High prevalence of bacterial vaginosis in adolescent girls in a tropical area of Ecuador," BJOG: An International Journal of Obstetrics \& Gynaecology, vol. 117, no. 2, pp. 225-228, 2010.

[13] D. M. T. Faustini, N. F. Novo, M. C. F. D. S. Cury, and Y. Juliano, "Programa de orientação desenvolvido com adolescentes em centro de saúde: conhecimentos adquiridos sobre os temas abordados por uma equipe multidisciplinar," Ciência é Saúde Coletiva, vol. 8, no. 3, pp. 783-790, 2003.

[14] J. W. Krashin, E. H. Koumans, A. C. Bradshaw-Sydnor et al., "Trichomonas vaginalis prevalence, incidence, risk factors and antibiotic-resistance in an adolescent population," Sexually Transmitted Diseases, vol. 37, no. 7, pp. 440-444, 2010.

[15] "Adolescence, an Age of Opportunity: The State of the World's Children 2011," New York, NY, USA, United Nations Children's Fund, 2011.

[16] R. P. Nugent, M. A. Krohn, and S. L. Hillier, "Reliability of diagnosing bacterial vaginosis is improved by a standardized method of gram stain interpretation," Journal of Clinical Microbiology, vol. 29, no. 2, pp. 297-301, 1991.

[17] M. D. S. Wanderley, E. M. S. Magalhães, and É. R. Trindade, "Avaliação Clínica e Laboratorial de Crianças e Adolescentes com Queixas Vulvovaginais," Revista Brasileira de Ginecologia e Obstetrícia, vol. 22, no. 3, pp. 147-152, 2000.

[18] M. M. Barousse, B. J. Van Der Pol, D. Fortenberry, D. Orr, and P. L. Fidel Jr., "Vaginal yeast colonisation, prevalence of vaginitis, and associated local immunity in adolescents," Sexually Transmitted Infections, vol. 80, no. 1, pp. 48-53, 2004.

[19] M. S. Almeida, D. S. Argôlo, J. S. Almeida Júnior, M. S. Pinheiro, and A. M. G. D. Brito, "Tricomoníase: prevalência no gênero feminino em Sergipe no biênio 2004-2005," Ciência \& Saúde Coletiva, vol. 15, supplement 1, pp. 1417-1421, 2010.

[20] C. G. Luppi, R. L. S. D. Oliveira, M. A. Veras, S. A. Lippman, H. Jones, C. H. D. Jesus et al., "Diagnóstico precoce e os fatores associados às infecções sexualmente transmissíveis em mulheres atendidas na atenção primária," Revista Brasileira de Epidemiologia, vol. 14, no. 3, pp. 467-477, 2011.

[21] U. Karaman, N. Karadağ, M. Atambay, N. B. Arserim Kaya, and N. U. Daldal, "A comparison of cytological and parasitological methods in the diagnosis of Trichomonas vaginalis," Turkiye Parazitol Derg, vol. 32, no. 4, pp. 309-312, 2008.

[22] A. M. Caliendo, J. A. Jordan, A. M. Green, J. Ingersoll, R. J. Diclemente, and G. M. Wingood, "Real-time PCR improves detection of Trichomonas vaginalis infection compared with culture using self-collected vaginal swabs," Infectious Diseases in Obstetrics and Gynecology, vol. 13, no. 3, pp. 145-150, 2005.

[23] M. Sutton, M. Sternberg, E. H. Koumans, G. McQuillan, S. Berman, and L. Markowitz, "The prevalence of Trichomonas vaginalis infection among reproductive-age women in the United States, 2001-2004," Clinical Infectious Diseases, vol. 45, no. 10, pp. 1319-1326, 2007.

[24] R. Crosby, R. J. DiClemente, G. M. Wingood et al., "Predictors of infection with Trichomonas vaginalis: a prospective study of low income African-American adolescent females," Sexually Transmitted Infections, vol. 78, no. 5, pp. 360-364, 2002.

[25] E. Rylander, A. L. Berglund, C. Krassny, and B. Petrini, "Vulvovaginal candida in a young sexually active population: prevalence and association with oro-genital sex and frequent pain at intercourse," Sexually Transmitted Infections, vol. 80, no. 1, pp. 54-57, 2004.

[26] M. S. Cohen, I. F. Hoffman, R. A. Royce et al., "Reduction of concentration of HIV-1 in semen after treatment of urethritis: implications for prevention of sexual transmission of HIV-1," The Lancet, vol. 349, no. 9069, pp. 1868-1873, 1997.

[27] M. Laga, A. Manoka, M. Kivuvu et al., "Non-ulcerative sexually transmitted diseases as risk factors for HIV-1 transmission in women: results from a cohort study," AIDS, vol. 7, no. 1, pp. 95-102, 1993.

[28] K. Chaijareenont, K. Sirimai, D. Boriboonhirunsarn, and O. Kiriwat, "Accuracy of Nugent's score and each Amsel's criteria 
in the diagnosis of bacterial vaginosis," Journal of the Medical Association of Thailand, vol. 87, no. 11, pp. 1270-1274, 2004.

[29] P. Zarakolu, N. N. Sahin Hodoglugil, F. Aydin, I. Tosun, A. Gozalan, and S. Unal, "Reliability of interpretation of gram-stained vaginal smears by Nugent's scoring system for diagnosis of bacterial vaginosis," Diagnostic Microbiology and Infectious Disease, vol. 48, no. 2, pp. 77-80, 2004.

[30] C. Tokyol, O. C. Aktepe, A. S. Cevrioglu, M. Altindis, and F. H. Dilek, "Bacterial vaginosis: comparison of Pap smear and microbiological test results," Modern Pathology, vol. 17, no. 7, pp. 857-860, 2004.

[31] J. P. Menard, C. Mazouni, F. Fenollar, D. Raoult, L. Boubli, and F. Bretelle, "Diagnostic accuracy of quantitative real-time PCR assay versus clinical and Gram stain identification of bacterial vaginosis," European Journal of Clinical Microbiology and Infectious Diseases, vol. 29, no. 12, pp. 1547-1552, 2010. 


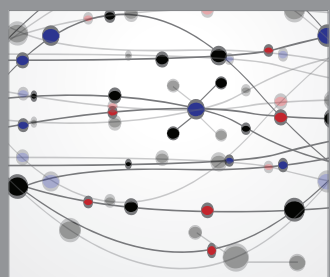

The Scientific World Journal
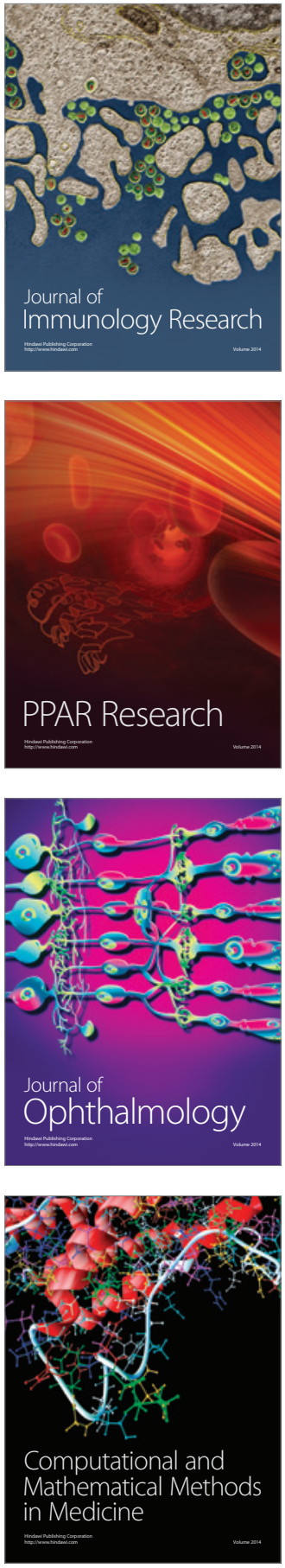

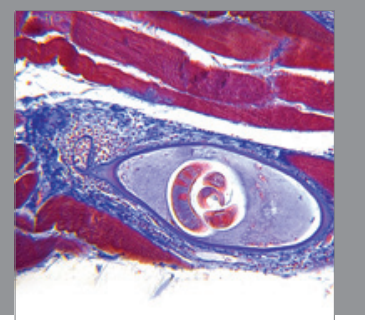

Gastroenterology

Research and Practice
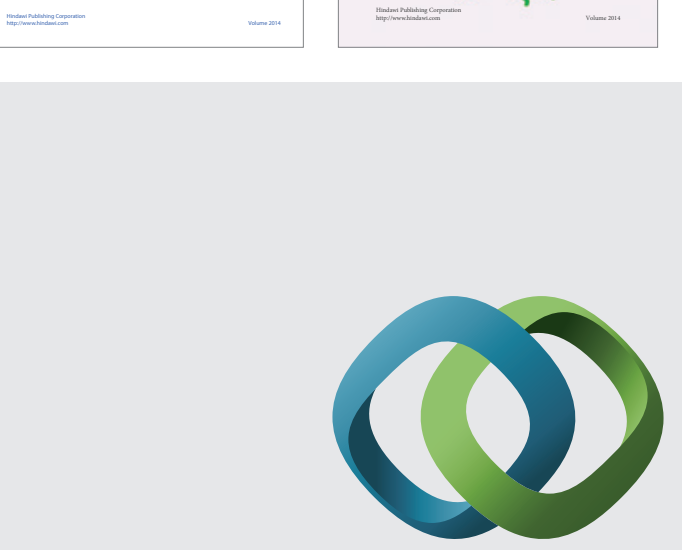

\section{Hindawi}

Submit your manuscripts at

http://www.hindawi.com
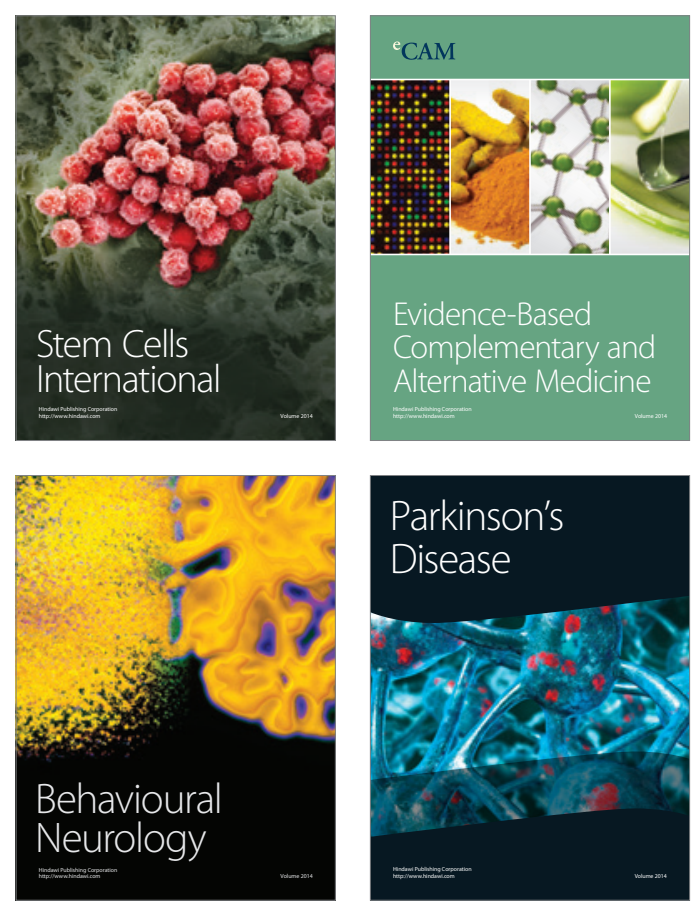

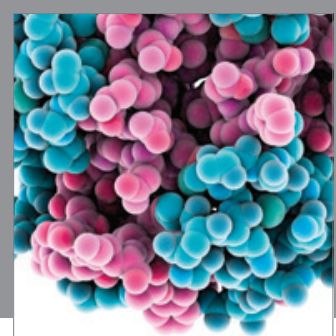

Journal of
Diabetes Research

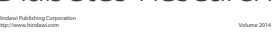

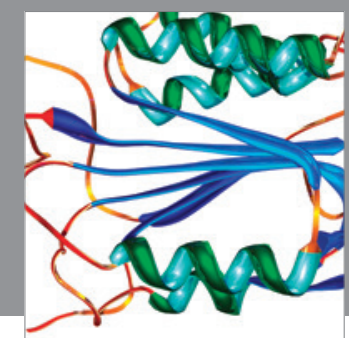

Disease Markers
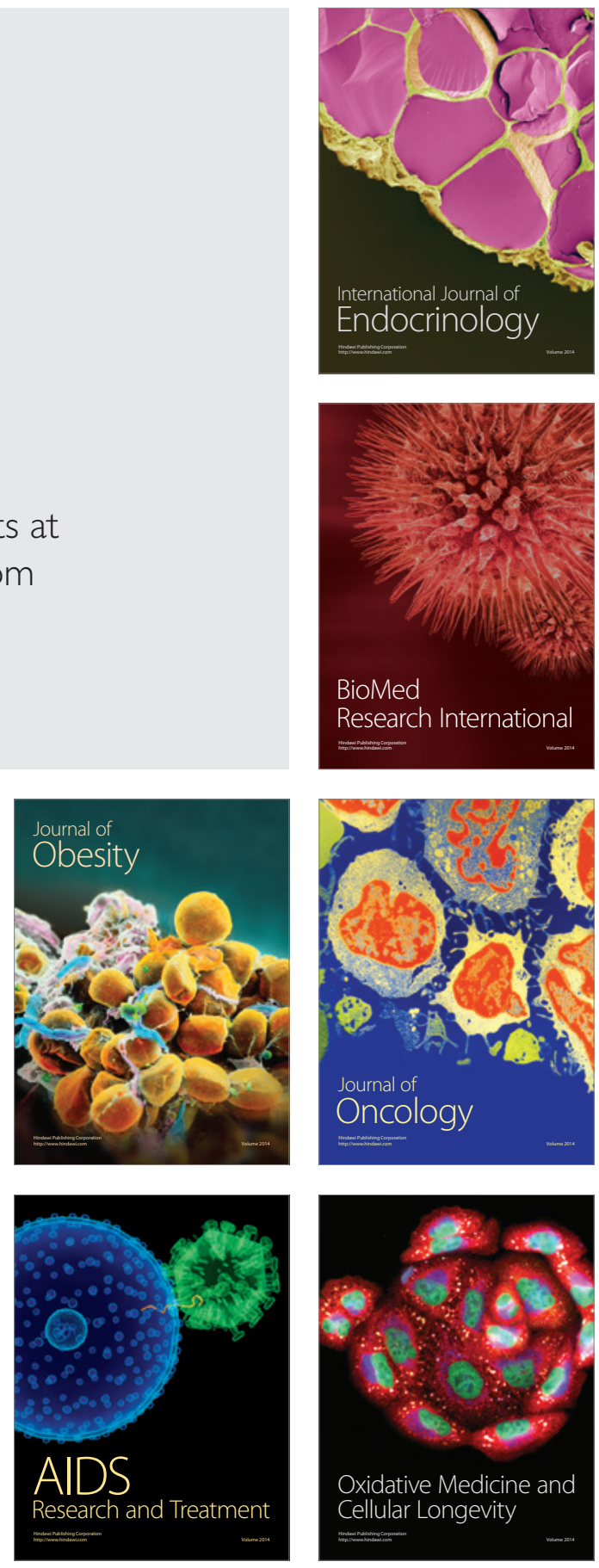